\title{
EDITORIAL
}

\section{The complex link between brain and heart in cardiac syndrome $X$}

\section{G A Lanza, F Crea}

Heart 2002;88:328-330

\section{There are new insights into the neural mechanisms responsible for enhanced cardiac pain perception in syndrome $X$}

See end of article for authors' affiliations

.....................

Correspondence to: Professor Filippo Crea, Istituto di Cardiologia, Università Cattolica del Sacro Cuore, L.go A. Gemelli, 800168 Roma, Italy; f.crea@tiscalinet.it $\mathrm{n}$ cardiac syndrome $\mathrm{X}$, the presence of ischaemic-like ST segment changes during chest pain, in the absence of epicardial coronary stenoses, suggests that myocardial ischaemia caused by coronary microvascular dysfunction is responsible for angina. ${ }^{1}$ This view is supported by the documentation of abnormalities in myocardial perfusion on radionuclide studies $^{23}$ and abnormal coronary blood flow response to vasoactive stimuli. ${ }^{4-7}$ Furthermore, several abnormalities able to cause microvascular dysfunction have been reported, including increased adrenergic function, ${ }^{8}$ increased stress induced coronary sinus release of endothelin-1, ${ }^{9}$ and increased activity of sodium-hydrogen countertransport. ${ }^{10}$ Yet several studies failed to show myocardial lactate production and left ventricular dysfunction $^{11-14}$ during angina and ST segment depression, thus casting some doubts on the ischaemic origin of chest pain and ECG changes. ${ }^{15}$

In 1988, Shapiro and colleagues reported the observation that syndrome $X$ patients refer chest pain during intra-atrial saline injection, suggesting that an abnormally increased perception of pain during usually painless cardiac stimuli could be the mechanism responsible for chest pain in cardiac syndrome $\mathrm{X} .{ }^{16}$ Several studies consistently confirmed this finding, ${ }^{17-20}$ lending further support to the hypothesis that a reduced cardiac pain threshold might be the predominant cause of the syndrome. These observations generated some new questions:

(1) Is enhanced perception of painful stimuli confined to the heart or is rather generalised?

(2) Where does the abnormality responsible for enhanced pain perception reside in the nervous system?

(3) What is the cause of this neural abnormality?

\section{CONFLICTING RESULTS}

As far as the first point is concerned, studies gave conflicting results, ${ }^{17}{ }^{21-24}$ but the only study which used a controlled, blind protocol failed to find evidence of generalised enhanced pain perception. ${ }^{17}$ Accordingly, using a randomised, double blind, "sham" controlled design, we found that enhanced cardiac pain perception is indeed present in syndrome $\mathrm{X}$ patients and is mainly confined to ventricular myocardium. ${ }^{25}$
In an interesting study published in a recent issue of Heart, Rosen and colleagues ${ }^{26}$ provide new insights into the neural mechanisms responsible for enhanced cardiac pain perception in syndrome $\mathrm{X}$. They performed dynamic $\mathrm{H}_{2}{ }^{15} \mathrm{O}$ positron emission tomography to map regional cerebral blood flow ( $\mathrm{rCBF}$ ) in eight syndrome $\mathrm{X}$ patients (six females) and in eight sex and age matched healthy controls. rCBF was evaluated at rest and during echocardiographic dobutamine stress test; the results were also compared with those obtained in a group of historical patients with stable angina and coronary artery disease (CAD) ( $\mathrm{n}=9$, two females). No control subject developed chest pain or ECG changes during dobutamine infusion. In contrast, all syndrome $\mathrm{X}$ patients developed typical anginal pain and ST segment depression, in the absence of detectable left ventricular wall motion abnormalities. rCBF distribution showed significant differences between syndrome $\mathrm{X}$ patients and controls, mainly consisting of an increased flow/activity in the right anterior insula, at the level of the frontal operculum junction in the former group. Of note, this latter finding also distinguished syndrome $\mathrm{X}$ from CAD patients. Thus, the authors propose that syndrome $X$ may be a "cortical pain syndrome", resulting in a "top down" process which facilitates the transmission to the cortex of pain stimuli which are usually blocked at the subcortical level.

This working hypothesis is certainly interesting, but it does not seem to be fully supported by the results of the study nor by recent reports on cardiac abnormalities in syndrome X. Firstly, as also recognised by the authors, the peculiar increase of right insula activity detected during chest pain in syndrome $\mathrm{X}$ patients does not necessarily have to be ascribed to an abnormal cortical influence, but it might be caused by afferent impulses originating from the heart, abnormal signal transmission and/or modulation at subcortical level(s), or by a variable combination of these abnormalities. Secondly, the comparison of rCBF between syndrome $\mathrm{X}$ and CAD patients during dobutamine induced chest pain presents limitations, as the latter were predominantly males, were studied with a different technique, and developed stress induced left ventricular dysfunction, all of which may have influenced the pattern of rCBF. Finally, rCBF measurements provide indirect information about changes in neural function and might miss functional changes of small neural areas. 


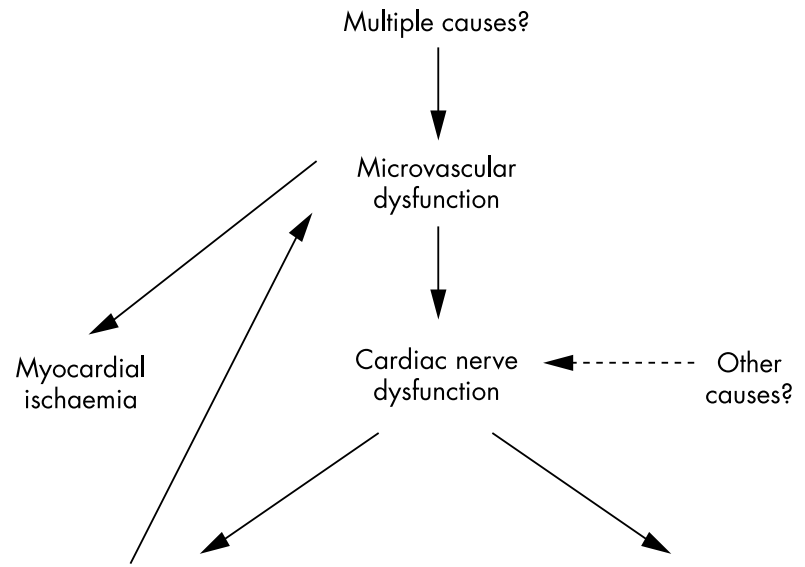

Efferent, sympathergic

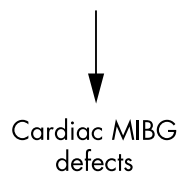

CARDIAC VERSUS CORTICAL ABNORMALITY

A comprehensive evaluation of data reported in the literature seems to support a peripheral (cardiac), rather than a central (cortical) abnormality responsible for the increased cardiac pain perception in syndrome $X$ patients. Indeed, most patients with syndrome $\mathrm{X}$ exhibit pronounced functional abnormalities in cardiac adrenergic nerve fibres, as indicated by severely impaired cardiac MIBG uptake. ${ }^{27}$ Furthermore, spinal cord stimulation, which is believed to act through enhancement of pain gate control in the dorsal horn, has been reported to improve anginal symptoms in patients with syndrome $\mathrm{X}^{28}$ thus suggesting a peripheral origin of painful stimuli. Finally, were a "top down" process responsible for the increased pain sensitivity, this should also involve, at least in a number of cases, other body tissues besides the heart, whereas this does not seem to be the case.

As for the cause(s) of the cardiac neural abnormality in syndrome $\mathrm{X}$, a plausible working hypothesis is shown in the fig 1 . The totality of current evidence suggests that coronary microvascular dysfunction severe enough to induce myocardial ischaemia in small myocardial regions is the primary abnormality of the syndrome, ${ }^{29}$ as recently confirmed using very sensitive markers of ischaemia, including transmyocardial lipoperoxide production ${ }^{30}$ and abnormalities in myocardial phosphorus metabolism ${ }^{31}$ during stress. Intermittent ischaemia in small myocardial regions might, in turn, induce functional alterations in both efferent and afferent cardiac adrenergic, and possibly vagal, nerve fibres. Changes in afferent nerve fibres might increase their sensitivity to cardiac stimuli which are usually unable to trigger a painful response, thus resulting in enhanced cardiac pain perception, in a way similar to that described for cutaneous hyperalgesia following peripheral sympathetic fibre injury. ${ }^{32}$ Additional mechanisms (for example, inflammation, metabolic abnormalities, etc) might also adversely affect cardiac nerve fibre function. ${ }^{33}$

In conclusion, Rosen and colleagues ${ }^{26}$ have shown, for the first time, that, in patients with syndrome $X$, angina and ST segment depression are associated with a transient increase in perfusion/activity in specific cerebral regions. In our opinion, these findings do not prove that cardiac syndrome $\mathrm{X}$ is a "cortical pain syndrome" as suggested by the authors. Their findings rather suggest that stress induced myocardial ischaemia in small regions scattered throughout the myocardium, undetectable by conventional diagnostic techniques, ${ }^{31}$ generate impulses which reach pain cortical centres in a way similar to
Figure 1 Working hypothesis about involvement of cardiac nerve endings in the pathophysiology of syndrome $X$. The primary abnormality of the syndrome is represented by a microvascular dysfunction, which can be caused by different mechanisms. Repeated episodic reduction of coronary blood flow could induce alterations in both efferent and afferent cardiac nerve fibres. Abnormal efferent adrenergic function may be represented by abnormal cardiac MIBG uptake, and may, in turn, influence microvascular function. Sensitisation of afferent cardiac nerves, on the other hand, may lead to abnormally increased cardiac pain perception. Other pathological mechanisms different from microvascular dysfunction might also be responsible for the cardiac nerve abnormalities, leading to the same clinical picture (see text for details). Modified from Lanza. ${ }^{33}$

that previously demonstrated by Rosen and colleagues in anginal CAD patients. ${ }^{34}$

\section{Authors' affiliations}

G A Lanza, F Crea, Istituto di Cardiologia, Università Cattolica del Sacro Cuore, Roma, Italy

\section{REFERENCES}

1 Likoff W, Segal BL, Kasparian H. Paradox of normal selective coronary arteriograms in patients considered to have unmistakable coronary heart disease. N Engl J Med 1967;276:1063-6.

2 Kaul S, Newell JB, Chesler DA, et al. Quantitative thallium imaging findings in patients with normal coronary angiographic findings and in clinically normal subjects. Am J Cardiol 1986;57:509-12.

3 Tweddel AC, Martin W, Hutton I. Thallium scans in syndrome X. $\mathrm{Br}$ Heart J 1992;68:48-50

4 Opherk D, Zebe H, Weihe E, et al. Reduced coronary dilatory capacity and ultrastructural changes of the myocardium in patients with angina pectoris but normal coronary arteriograms. Circulation $1981 ; 63: 817-25$

5 Cannon RO, Watson RM, Rosing DR, et al. Angina caused by reduced vasodilator reserve of the small coronary arteries. J Am Coll Cardiol 1983;1:1359-73.

6 Egashira K, Inou T, Hirooka Y, et al. Evidence of impaired endothelium-dependent coronary vasodilation in patients with angina pectoris and normal coronary angiograms. N Engl J Med 1993;328: 1659-64.

7 Chauhan A, Mullins PA, Petch MC, et al. Effect of hyperventilation and mental stress on coronary blood flow in syndrome $\mathrm{X}$. Br Heart J 1993:69:516-24

8 Montorsi P, Fabblocchi F, Loaldi A, et al. Coronary adrenergic hyperreactivity in patients with syndrome $X$ and abnormal electrocardiogram at rest. Am J Cardiol 1991;68:1698-703.

9 Lanza GA, Lüscher TF, Pasceri V, et al. Effects of atrial pacing on arterial and coronary sinus endothelin-1 levels in syndrome X. Am J Cardiol 1999;84: $1187-91$.

10 Gaspardone A, Ferri C, Crea F, et al. Enhanced activity of sodium-lithium countertransport in patients with cardiac syndrome $\mathrm{X}$ : a potential link between cardiac and metabolic syndrome X. J Am Coll Cardiol 1998;32:2031-4.

11 Arbogast R, Bourassa MG. Myocardial function during atrial pacing in patients with angina pectoris and normal coronary arteriograms. Comparison with patients having significant coronary artery disease. Am J Cardiol 1973;32:257-63.

12 Nihoyannopoulos P, Kaski JC, Crake T, et al. Absence of myocardial dysfunction during stress in patients with syndrome X. J Am Coll Cardiol 1991;18:1463-70.

13 Camici PG, Marraccini P, Lorenzoni R. Coronary hemodynamics and myocardial metabolism in patients with syndrome $X$ : response to pacing stress. J Am Coll Cardiol 1991;17:1461-70.

14 Panza JA, Laurienzo JM, Curiel RV. Investigation of the mechanism of chest pain in patients with angiographically normal coronary arteries using transesophageal dobutamine stress echocardiography. J Am Coll Cardiol 1997;29:293-301. 
15 Cannon RO, Camici PG, Epstein SE. Pathophysiological dilemma of syndrome X. Circulation 1992;85:883-92.

16 Shapiro LM, Crake T, Poole-Wilson PA. Is altered cardiac sensation responsible for chest pain in patients with normal coronary arteries? Clinical observations during cardiac catheterization. BM 1988;296:170-1.

17 Cannon RO, Quyyumi AA, Schenke WH, et al. Abnormal cardiac sensitivity in patients with chest pain and normal coronary arteries. J Am Coll Cardiol 1990; 16:1359-66.

18 Chauhan A, Mullins PA, Thuraisingham SI, et al. Abnormal cardiac pain perception in syndrome X. J Am Coll Cardiol 1994;24:329-35.

19 Lagerquist B, Sylvén C, Waldenstrom A. Lower threshold for adenosine-induced chest pain in patients with angina and normal coronary angiograms. Br Heart J 1992;68:282-5.

20 Eriksson B, Svedenhag J, Martinsson A, et al. Effect of epinephrine infusion on chest pain in syndrome $X$ in the absence of signs of myocardial ischemia. Am J Cardiol 1995;75:241-5.

21 Turiel M, Galassi AR, Glazier JJ, et al. Pain threshold and tolerance in women with syndrome $\mathrm{X}$ and women with stable angina pectoris. Am J Cardiol 1987;60:503-7.

22 Rosen SD, Uren NG, Kaski JC, et al. Coronary vasodilator reserve, pain perception, and sex in patients with syndrome X. Circulation 1994;90:50-60.

23 Frøbert $\mathrm{O}$, Arendt-Nielsen L, Bak P, et al. Pain perception and brain evoked potentials in patients with angina despite normal coronary angiograms. Heart 1996;75:436-41.

24 Lanza GA, Pasceri V, Colonna G, et al. Cardiac autonomic function and sensitivity to pain in post-menopausal women with angina and normal coronary arteries. Am J Cardiol 1997;79:1174-9.
25 Pasceri V, Lanza GA, Buffon A, et al. Role of abnormal pain sensitivity and behavioral factors in determining chest pain in syndrome X. J Am Coll Cardiol 1998;31:62-6

26 Rosen SD, Paulesu E, Wise RJS, et al. Central neural contribution to the perception of chest pain in cardiac syndrome X. Heart 2002;87:513-9.

27 Lanza GA, Giordano AG, Pristipino C, et al. Abnormal cardiac adrenergic nerve function in patients with syndrome $X$ detected by $\left[{ }^{123} \mid\right]$ metaiodobenzylguanidine myocardial scintigraphy. Circulation 1997;96:821-6.

28 Lanza GA, Sestito A, Sandric S, et al. Spinal cord stimulation in patients with refractory anginal pain and normal coronary arteries. Ital Heart J $2001 ; 2: 25-30$.

29 Maseri A, Crea F, Kaski JC, et al. Mechanisms of angina pectoris in syndrome X. J Am Coll Cardiol 1991;17:499-506.

30 Buffon A, Rigattieri S, Santini SA, et al. Myocardial ischemia-reperfusion damage after pacing-induced tachycardia in patients with cardiac syndrome X. Am J Physiol Heart Circ Physiol 2000;279:H2627-33.

31 Buchthal SD, den Hollander JA, Merz CNB, et al. Abnormal myocardial phosphorus-31 nuclear magnetic resonance spectroscopy in women with chest pain but normal coronary angiograms. N Engl J Med 2000;342:829-35.

32 Baron R, Maier C. Reflex sympathetic dystrophy: skin blood flow, sympathetic vasoconstrictor reflexes and pain before and after surgical sympathectomy. Pain 1996;67:317-26.

33 Lanza GA. Abnormal cardiac nerve function in syndrome X. Herz 1999;24:97-106.

34 Rosen SD, Paulesu E, Frith CD, et al. Central neural correlates of angina pectoris as a model of visceral pain. Lancet 1994;344:147-50.

\section{IMAGES IN CARDIOLOGY}

\section{Microvascular obstruction and missed infarction}

A

68 year old retired physician with no previous cardiac history presented with a four hour history of central crushing chest pain. His pulse was 90 beats/min, blood pressure 170/90 $\mathrm{mm} \mathrm{Hg}$, with no evidence of heart failure. His ECG demonstrated right bundle branch block, and the troponin $\mathrm{T}$ was raised at $0.4 \mu \mathrm{g} / \mathrm{ml}$ (normal $<0.1 \mu \mathrm{g} / \mathrm{ml}$ ). Over the next 24 hours he had further chest pain. Cardiac $x$ ray angiography demonstrated normal left ventricular function and minor non-flow limiting disease of the mid left anterior descending (LAD) and right coronary (RCA) arteries.

Cardiovascular magnetic resonance (CMR) was performed. The basal septum was akinetic on cine imaging. After gadolinium-DTPA, in the early phase ( $<5$ minutes) there was extensive microvascular obstruction (arrow) in the territory of the first septal branch of the LAD. During the late phase ( $>10$ minutes), these areas still persist but with surrounding hyperenhancement (arrows).

Gadolinium-DTPA is a small molecule that diffuses into the extracellular fluid making the tissue appear bright on CMR. It does not cross intact cell membranes. Because of myocyte death, myocardial infarction tissue has an increased volume of extracellular fluid and slower gadolinium kinetics than normal myocardium, so in the late phase after a bolus it appears bright and hyperenhanced. In some infarcts, as in this case, gadolinium may fail to enter the infarct core because of capillary collapse and microvascular obstruction, and this is best seen in the early phase. If microvascular obstruction is extensive there will be no flow down the subtending coronary artery, even if the artery is re-opened-the no-reflow phenomenon. Microvascular obstruction is associated with a worse prognosis. The transmural extent of infarction predicts subsequent functional recovery and the potential for recovery after revascularisation.

In the light of the CMR findings, the $x$ ray angiography was reviewed. The first septal did not opacify and a stump off the LAD was noted.

This case illustrates how CMR can make the diagnosis of coronary disease where angiography proved difficult to interpret because of ostial occlusion of a side branch vessel. The diagnosis was acute

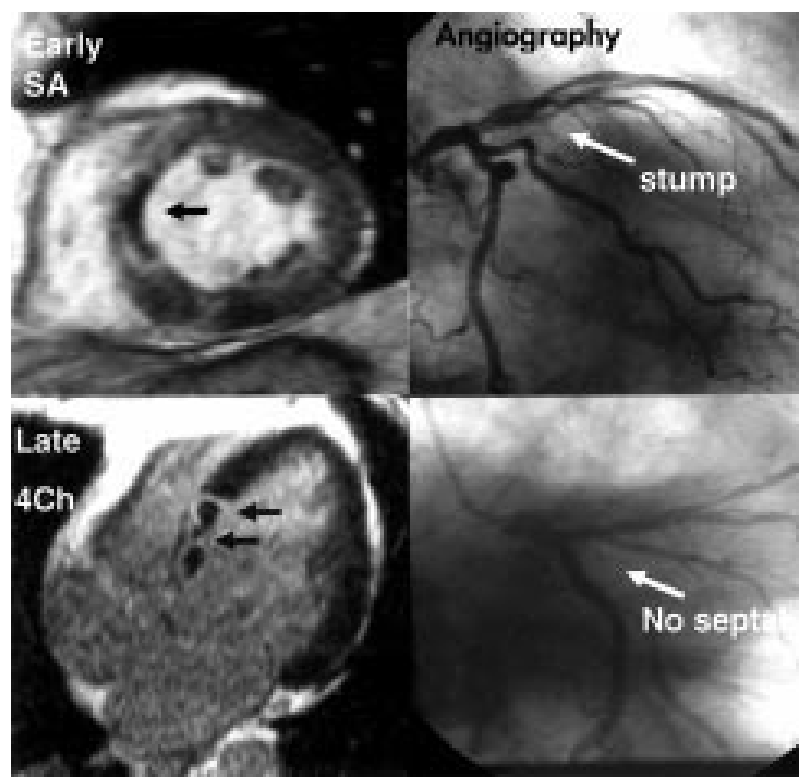

myocardial infarction because of occlusion of the first septal artery with microvascular obstruction.

J C C Moon

P J Oldershaw

D J Pennell

j.moon@rbh.nthames.nhs.uk 